University of Nebraska - Lincoln

DigitalCommons@University of Nebraska - Lincoln

Biological Systems Engineering: Papers and

Publications

Biological Systems Engineering

2011

\title{
High temperature dilute acid pretreatment of coastal Bermuda grass for enzymatic hydrolysis
}

Arthur P. Redding

North Carolina State University

Ziyu Wang

North Carolina State University

Deepak R. Keshwani

University of Nebraska-Lincoln, dkeshwani2@unl.edu

Jay J. Cheng

North Carolina State University, jay_cheng@ncsu.edu

Follow this and additional works at: https://digitalcommons.unl.edu/biosysengfacpub

Part of the Biological Engineering Commons

Redding, Arthur P.; Wang, Ziyu; Keshwani, Deepak R.; and Cheng, Jay J., "High temperature dilute acid pretreatment of coastal Bermuda grass for enzymatic hydrolysis" (2011). Biological Systems Engineering: Papers and Publications. 204.

https://digitalcommons.unl.edu/biosysengfacpub/204

This Article is brought to you for free and open access by the Biological Systems Engineering at DigitalCommons@University of Nebraska - Lincoln. It has been accepted for inclusion in Biological Systems Engineering: Papers and Publications by an authorized administrator of DigitalCommons@University of Nebraska Lincoln. 
Published in Bioresource Technology 102 (2011), pp. 1415-1424; doi:10.1016/j.biortech.2010.09.053 Copyright @ 2010 Elsevier Ltd. Used by permission. Bioresource Technology journal homepage: http://www.elsevier.com/locate/biortech

Submitted June 14, 2010; revised September 11, 2010; accepted September 14, 2010; published online September 19, 2010.

\title{
High temperature dilute acid pretreatment of coastal Bermuda grass for enzymatic hydrolysis
}

\author{
Arthur P. Redding, ${ }^{1}$ Ziyu Wang, ${ }^{1}$ Deepak R. Keshwani, ${ }^{2}$ Jay J. Cheng ${ }^{1}$ \\ 1. Department of Biological and Agricultural Engineering, North Carolina State University, Raleigh, NC 27695-7625, USA \\ 2. Department of Biological Systems Engineering, University of Nebraska-Lincoln, Lincoln, NE 68583-0726, USA
}

Corresponding author - J. J. Cheng, tel 919 515-6733, fax 919 515-7760, email jay_cheng@ncsu.edu

\begin{abstract}
Dilute sulfuric acid was used to pretreat coastal Bermuda grass at high temperature prior to enzymatic hydrolysis. After both pretreatment and enzymatic hydrolysis processes, the highest yield of total sugars (combined xylose and glucose) was $97 \%$ of the theoretical value. The prehydrolyzate liquor was analyzed for inhibitory compounds (furfural, hydroxymethylfurfural (HMF)) in order to assess potential risk for inhibition during the following fermentation. Accounting for the formation of the inhibitory compounds, a pretreatment with 1.2\% acid at $140{ }^{\circ} \mathrm{C}$ for $30 \mathrm{~min}$ with a total sugar yield of $94 \%$ of the theoretical value may be more favorable for fermentation. From this study, it can be concluded that dilute sulfuric acid pretreatment can be successfully applied to coastal Bermuda grass to achieve high yields of monomeric glucose and xylose with acceptable levels of inhibitory compound formation.
\end{abstract}

Keywords: coastal Bermuda grass, dilute sulfuric acid pretreatment, enzymatic hydrolysis, furfural, hydroxymethylfurfural

\section{Introduction}

Due to a lack of resource sustainability of fossil fuels as well as negative environmental effects from emissions, research is being done to find a liquid fuel for use as a gasoline replacement. In the United States (US) ethanol appears to be a good near-term option. Ethanol is already mixed with gasoline at a level of $10 \%$ and support from vehicle manufacturers has resulted in vehicles that can use up to an $85 \%$ ethanol-15\% gasoline mixture. Currently, ethanol is mainly produced from corn starch in the US, but competition with corn for food and limitations on arable land for expanding the cultivation of corn place a ceiling on the ethanol producible lower than what is required to replace gasoline (Sun and Cheng, 2002). This has spurred research into cellulosic feedstocks for ethanol production. Lignocellulosic materials are abundant nearly everywhere opening the potential for different geographic regions to take advantage of locally abundant cellulosic feedstocks for ethanol production. While corn ethanol simply requires a hot water pretreatment followed by enzymatic hydrolysis using inexpensive amylases, lignocellulosic materials require a harsher pretreatment step followed by hydrolysis using more costly cellulases (Solomon et al., 2007). Currently, pretreatment, enzymatic hydrolysis, and fermentation are the key areas being researched to make lignocellulosic feedstocks competitive with corn for the production of ethanol and this study focuses on the pretreatment step. Of the many pretreatment technologies covered by a number of review papers, dilute acid pretreatment stands out having been already examined in a large number of studies as well as appearing more economically feasible at larger scale than other current pretreatment technologies (Sun and Cheng, 2002; Moiser et al., 2005; Eggeman and Elander, 2005).

In the southeastern US, coastal Bermuda grass (CBG) (Cynodon dactylon $\mathrm{L}$.) is grown by hog producers as part of required nutrient management practices to remove nitrogen and phosphorus from hog waste. With a yield of 6-10 dry tons per acre each year and an active cropping system in place, CBG is potentially a viable lignocellulosic feedstock option for ethanol production in the southeastern US (Holtzapple et al., 1994). Sun and Cheng (2005) investigated the dilute sulfuric acid pretreatment of coastal Bermuda grass at $121{ }^{\circ} \mathrm{C}$ over a range of acid concentrations $(0.6-1.5 \% \mathrm{w} / \mathrm{w})$ and residence times (30-90 min). Optimal pretreatment conditions were found to be $1.2 \%$ acid for $60 \mathrm{~min}$ yielding about $70 \%$ of the total sugars from the biomass. Other studies using dilute acid pretreatment with different feedstocks have shown that increasing temperature increases sugar yields and can decrease the residence time and acid concentration required to generate the same yields at lower temperatures and longer residence times (Lloyd and Wyman, 2005; Saha et al., 2005, 2008). Based on results from Sun and Cheng (2005) and the review of research done on other feedstocks using dilute acid at temperatures higher than $121{ }^{\circ} \mathrm{C}$, this study was performed to examine 
if higher sugar yields from CBG could be generated at higher temperatures, to identify the effects of temperature, concentration, residence time, and the interactions between these factors on sugar yields, and to assess what pretreatment conditions would be the best in the pretreatment of CBG.

\section{Methods}

\subsection{Biomass handling and storage}

CBG was obtained in 2007 from Central Crops Research Station located in Clayton, NC, courtesy of Dr. Joe Burns of the Crop Science Department at North Carolina State University. The collected CBG was stored in loose bale at ambient room temperature in a large plastic bag. Before used for pretreatment, the CBG was ground to particle sizes no greater than $2 \mathrm{~mm}$ using a Wiley Laboratory Mill (Model No. 4, Thomas, Philadelphia, PA, USA) fitted with a $2 \mathrm{~mm}$ screen. The resulting ground biomass was stored in sealed bags at ambient room temperature in the lab until used.

\subsection{Composition analysis of raw biomass}

Prior to any pretreatment, the CBG was analyzed for its composition. The moisture content was determined using a 105 ${ }^{\circ} \mathrm{C}$ oven to dry the biomass according to the procedure outlined in National Renewable Energy Laboratory (NREL) laboratory analytical procedure (LAP) "Determination of Total Solids in Biomass" (Sluiter, 2005). Extractive components like waxes, chlorophyll, non-structural sugars, and other minor components were quantified using a Soxhlet extractor, a 2:1 toluene:ethanol mixture, and $24 \mathrm{~h}$ reflux time (Silverstein, 2004; Han and Rowell, 1997). The extractive-free biomass was then examined for the structural carbohydrates, i.e. glucan, xylan, arabinan, and galactan as well as acid insoluble lignin (AIL) and acid soluble lignin (ASL) using the NREL LAP "Determination of Structural Carbohydrates and Lignin in Biomass" (Sluiter, 2006a). The ash content of the biomass was determined using a benchtop muffle furnace in accordance with NREL LAP "Determination of Ash in Biomass" (Sluiter, 2005).

\subsection{Pretreatment}

A factorial experimental design was developed to examine the effect of the pretreatment conditions, i.e. reaction temperature, acid concentration and residence time, on the sugar yields in both the prehydrolyzate and the hydrolyzate liquors as well as the generation of sugar degradation products in the prehydolyzate liquor. Factor levels of the experimental design are based on literature review and previous work on the dilute acid pretreatment of CBG done by Sun and Cheng (2005). Sulfuric acid concentrations of $0.3 \%, 0.6 \%, 0.9 \%$, and $1.2 \%(\mathrm{w} / \mathrm{w})$ were examined at temperatures of $120,140,160$, and $180{ }^{\circ} \mathrm{C}$ and residence times of 5, 15, 30, and $60 \mathrm{~min}$.

Dilute sulfuric acid pretreatment was performed in vessels constructed from threaded 4 in. long by 0.75 in. inner diameter 306 stainless steel pipe nipples capped on both ends with threaded 306 stainless steel pipe caps. The parts used to construct the vessels were purchased from McMaster Carr (Santa Fe Springs, CA, USA). Sulfuric acid was prepared on a w/w basis from a $96 \%$ stock solution beforehand and stored in a reagent bottle for continued use. Six vessels (two treatments in triplicate) were loaded at a ratio of 10 parts dilute acid to one part dry raw biomass ( $\mathrm{w} / \mathrm{w}$ ) (30 $\mathrm{ml}$ acid and $3 \mathrm{~g}$ biomass). The 7 th vessel was loaded with de-ionized (DI) water instead of dilute acid in the same $10 \%$ solids loading as the other vessels and sealed with a cap containing a plug k-type thermocouple
(Model TC-K-NPT-G-72-SMP, Omega, Stamford, CT, USA), served as a temperature monitor for the approximate internal temperature of the other reaction vessels.

A Fisher Scientific High-Temp Bath (Model 160A, Fisher Scientific, Dubuque, Iowa, USA) was used to indirectly heat the vessels with silicone oil (Poly(dimethylsiloxane), $d=0.96$ ) as a heat transfer fluid. A k-type thermocouple temperature probe was submerged in the oil in order to monitor the oil temperature and both this probe and the probe in the vessel were connected to an Extech Easyview Thermometer (Model 11A, Extech, Waltham, MA, USA) which displayed the temperature readings. The oil was heated to $20^{\circ} \mathrm{C}$ higher than the desired set-point for the reaction to shorten preheat time. Once the oil reached the desired temperature, the seven vessels were added to the bath and the time of this addition was recorded. The blank vessel's internal temperature was then monitored along with the temperature of the oil until both reached the desired reaction temperature at which time it was inferred that all of the vessels were at the desired temperature. Heating was manually controlled using the dial on the oil bath to turn the heating element on and off in order to keep the time it took to heat the vessels to the desired temperature to $12 \mathrm{~min}$ plus or minus $2 \mathrm{~min}$. Once the proper internal temperature in the vessels was reached, the residence time began and upon completion of the residence time, the vessels were quickly removed from the oil bath and placed in a bin of cool water where they were cooled to less than $40^{\circ} \mathrm{C}$ within $5 \mathrm{~min}$.

After pretreatment, the vessels were opened up for the filtration step. A Welch Duo-Seal vacuum pump (Model 1HAB25B-M100X, GAST Manufacturing, Inc., Benton Harbor, MI, USA) was used to pull a vacuum across a Whatman P8 filter paper in a standard vacuum flask and buchner filter funnel setup. The contents of each vessel were emptied onto a pre-weighed filter paper associated with that particular sample. Sixty milliliters of de-ionized (DI) water at room temperature was used to rinse the biomass and ensure the collection of all the sugars hydrolyzed in the pretreatment step. The total amount of filtrate and wash water was measured in a graduated cylinder and a portion was stored in labeled $15 \mathrm{ml}$ tubes and frozen at $-20^{\circ} \mathrm{C}$. The solids on the filter paper were rinsed with an additional $140 \mathrm{ml}$ of room temperature DI water and then placed into an appropriately labeled bag for storage at 4 ${ }^{\circ} \mathrm{C}$. These bags were weighed before and after the addition of biomass for use in calculating solid loss later. The filter paper was dried for $24 \mathrm{~h}$ at $105^{\circ} \mathrm{C}$ and then weighed to account for biomass remaining on the filter paper.

\subsection{Enzymatic hydrolysis}

Enzymatic hydrolysis was preformed in $50 \mathrm{ml}$ centrifuge tubes maintained at $55^{\circ} \mathrm{C}$ and $155 \mathrm{rpm}$ agitation for $72 \mathrm{~h}$ by an automated shaking water bath (Model C76, New Brunswick Scientific, Edison, NJ, USA). Each tube was first loaded with the retained rinsed pretreated biomass weighed to account for moisture so that each tube received the equivalent of $0.5 \mathrm{~g}$ of dry biomass. Novozymes North America (Franklinton, NC, USA) provided the cellulase, NS-50013, and the cellobiase, NS-50010, which were determined using an assay procedure derived from Ghose (1987) to have activities of 76.44 FPU/ $\mathrm{ml}$ (filter paper units, where one unit equates the amount of enzyme required to produce $1 \mu \mathrm{mol}$ of glucose per minute from filter paper) and 283.1 CBU/ml (cellobiase units, where one unit equates the amount of enzyme required to generate $2 \mu \mathrm{mol}$ of glucose per minute from cellobiose), respectively. The enzymes were loaded in excess at 40 FPU of cellulase per gram of dry biomass and $70 \mathrm{CBU}$ of cellobiase per gram of dry biomass to avoid any limitation in monomeric sugar production caused by enzyme deficiency. Sodium azide, $0.3 \%$ (w/v), 
was added to inhibit microbial growth. Sodium azide at $0.3 \%$ $(\mathrm{w} / \mathrm{v})$ was chosen according to the previous relevant studies in the literature (Kim and Holtzapple, 1987; Sun and Cheng, 2005). Accounting for the amount of moisture in the biomass, the sodium azide, and the enzymes, the total amount of liquid in each tube was brought up to $15 \mathrm{ml}$ using a $0.05 \mathrm{M}$ sodium citrate buffer to maintain a $\mathrm{pH}$ of 4.8 during the enzymatic hydrolysis step. The primary purpose of the sodium citrate buffer was to maintain the $\mathrm{pH}$ at 4.8 which is an ideal $\mathrm{pH}$ for enzyme activity during the enzymatic hydrolysis (Ghose, 1987; Kim and Holtzapple, 1987; Sun and Cheng, 2005).

\subsection{Sugar analysis}

The hydrolyzate and prehydrolyzate were analyzed using a high performance liquid chromatography (HPLC) system to quantify the sugar monomers. The HPLC was also used to quantify prehydolyzate sugar degradation products. The NREL LAP "Determination of Sugars, Byproducts, and Degradation Products in Liquid Fraction Process Samples" was the foundation for the HPLC sample preparation and analysis procedure used in this study (Sluiter, 2006b). HPLC parameters used in this study which differ from those outlined in the NREL LAP were developed by Novozymes who ran the samples for this study on their HPLC units. An Aminex HPX-87P column coupled with a refractive index detector was used to distinguish amounts of glucose, xylose, galactose, arabinose in the hydrolyzate samples. Samples were prepared from the $\mathrm{pH}$ 4.8 hydrolyzate, diluted by four times, and filtered through a $2 \mu \mathrm{m}$ syringe filter. The column was run at $80^{\circ} \mathrm{C}$ with a flow rate of $0.6 \mathrm{ml} / \mathrm{min}$ using HPLC grade water as a mobile phase. Samples injections were $10 \mu \mathrm{L}$ and the runtime was $35 \mathrm{~min}$. A 25 min post-runtime was included to clear late-eluting compounds from the column. For the prehydrolyzate samples, an Aminex HPX-87H column was used to quantify the levels of glucose, xylose, furfural, 5-hydroxyfuranmethal (HMF), formic acid, and levulinic acid. Samples were prepared from the prehydrolyzate which had a $\mathrm{pH}$ of less than two and filtered through a $2 \mu \mathrm{m}$ syringe filter. This column was run at $65{ }^{\circ} \mathrm{C}$ with a flow rate of $0.7 \mathrm{~mL} / \mathrm{min}$. Sample injections were run for $51 \mathrm{~min}$. Total sugars, monomeric sugars, and degradation products were calculated on a per gram of raw biomass basis.

\subsection{Lignin analysis of pretreated biomass}

The retained solid biomass was analyzed for acid insoluble lignin and acid soluble lignin composition in the same manner as the raw biomass was analyzed using the NREL LAP "Determination of Structural Carbohydrates and Lignin in Biomass" (Sluiter, 2006a).

\subsection{Statistical analysis}

Although triplicates were collected, the data had a number of outliers which appeared to be due to unequal heating during pretreatment, enzymatic hydrolysis error, or analysis error. As a result many triplicates had two sets of measured values very close and one set with a clear difference. To remedy this, one sample was removed systematically from each triplicate. The remaining data was run through the GLM procedure in SAS 9.1.3 (SAS Institute Inc., Cary, NC, USA) to perform an analysis of variance (ANOVA) to identify statistically significant effects from each of the factors as well as interactions of the factors. The interaction effect combinations included two-way interactions between temperature and concentration, temperature and time, concentration and time, and the three-way interaction among temperature, concentration, and time. The data was adjusted using Tukey's adjustment and significant differences were evaluated where $p<0.01(\alpha=0.01)$. MATLAB 7.6.0.324 R2008a (The MathWorks, Natick, MA, USA) was used to generate contour plots for visual analysis of the data.

\section{Results and discussion}

\subsection{Composition of coastal Bermuda grass}

The CBG was examined for carbohydrate, lignin, extractive, and ash composition according to Wang et al. (2010) and Sun and Cheng (2005) with the resulting dry weight percentages shown in Table 1. The two sets of composition data are different from the set from Sun and Cheng (2005) reporting a greater amount of sugar with $6.77 \%$ more glucan and $3.49 \%$ more $x y-$ lan than the set reported by Wang et al. (2010). This difference can likely be attributed to the difference in harvest time, crop inputs, or the fact that Wang et al. (2010) did the analysis on extractive-free biomass rather than the raw biomass. In removing the extractives, nonstructural carbohydrates could have also been removed. This study was run in parallel with the study done by Wang et al. (2010) and used the same CBG stock and composition data.

Glucan, xylan, arabinan, and galactan can be converted respectively to glucose, xylose, arabinose, and galactose using anhydro corrections of 0.90 for six-carbon sugars and 0.88 for five-carbon sugars which accounts for the removal of a water molecule. In this study arabinose and galactose concentrations in both prehydrolyzate and hyrolyzate are negligible. References to 'total sugars' will only include the sum of glucose and xylose for simplification. The theoretical maximum release of glucose is $284.3 \mathrm{mg} / \mathrm{g}$ of raw biomass (dry). The theoretical maximum for xylose is $180.5 \mathrm{mg} / \mathrm{g}$ of raw biomass (dry). The theoretical maximum for total sugars is therefore $464.8 \mathrm{mg} / \mathrm{g}$ of raw biomass. Further yield calculations will be based upon these theoretical values.

\subsection{Dilute acid pretreatment}

The pretreatment step had two major outputs, the pretreated CBG solids and the prehydrolyzate liquor. The solids were analyzed for both acid insoluble lignin and acid soluble lignin. The prehydrolyzate liquor was analyzed for carbohydrates and carbohydrate degradation products.

\subsubsection{Lignin reduction}

Dilute acid pretreatment works primarily by hydrolyzing hemicellulose into sugars (mostly xylose) from the biomass structure (Moiser et al., 2005). However, lignin also undergoes simultaneous degradation and accumulation reactions during an acid pretreatment (Pearl, 1967). Yang and Wyman (2004) showed that the net prevailing reaction in a batch reactor appeared to correspond to the severity of the acid pretreatment. While intermediate pretreatment severities tended to correspond with higher measured lignin removal (20-30\%), there was also data showing little or no lignin removal. Additionally, both lower and higher severity acid pretreatments tended to show either no lignin removal or apparent lignin accumulation above that measured in the initial biomass composition analysis. Yang and Wyman (2004) suggested that these unclear lignin measurements were a complication of using a batch reactor. They showed that using a flow-through reactor where solubilized lignin was removed from the system as the pretreatment progressed resulted in measured lignin removal of up to $85 \%$ that was clearly positively linearly correlated with the pretreatment severity. Since batch reactors were used in this study, the lignin values measured after pretreatments follow the general trend presented by Yang and Wyman (2004) 

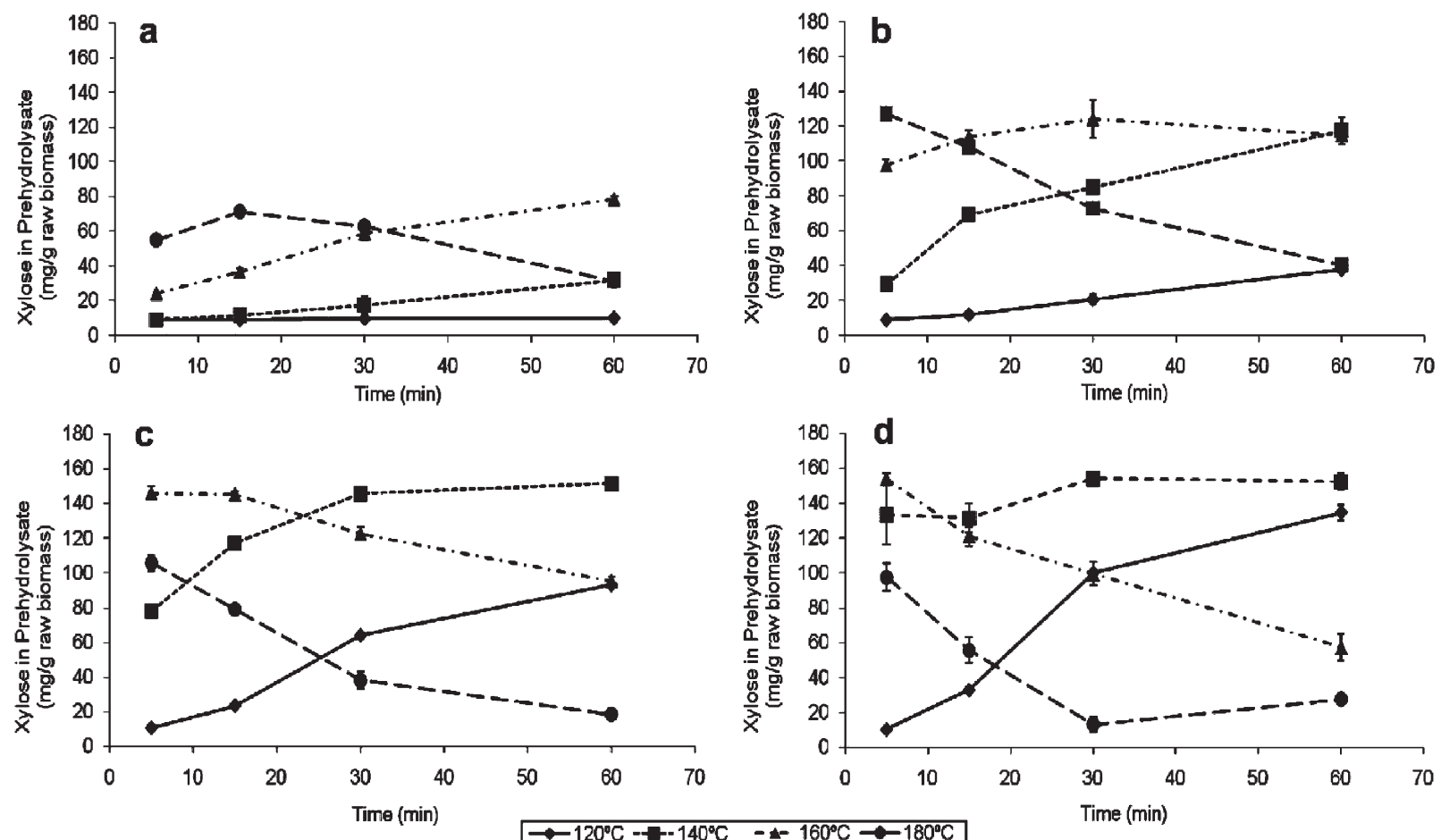

Figure 1. Monomeric xylose measured in the prehydrolyzate after pretreatment as a function of time and temperature for (a) $0.3 \%$, (b) $0.6 \%$, (c) $0.9 \%$, and (d) $1.2 \%$ sulfuric acid concentration $(w / w)$.

Table 1. Composition of coastal Bermuda grass.

\begin{tabular}{lrr}
\hline Component & $\begin{array}{r}\text { \% Weight of dry biomass } \\
\text { (Wang et al. (2010)) }\end{array}$ & $\begin{array}{r}\text { \% Weight of dry biomass } \\
\text { (Sun and Cheng (2005)) }\end{array}$ \\
\hline Glucan & 25.59 & 32.36 \\
Xylan & 15.88 & 19.37 \\
Arabinan & 1.95 & 4.33 \\
Galactan & 1.46 & 1.09 \\
Acid insoluble lignin & 15.37 & 20.33 \\
Acid soluble lignin & 3.96 & $\mathrm{ND}$ \\
Extractives & 4.17 & $\mathrm{ND}$ \\
Ash & 6.6 & 4.17 \\
\hline
\end{tabular}

for batch reactors, which made it difficult to elucidate the specific effects of the pretreatment on the lignin portion of the biomass. As a result, acid soluble lignin and acid insoluble lignin data have not been reported in the body of this paper, however, it can be inferred that acid pretreatment in a batch reactor may disrupt the structure of lignin.

\subsubsection{Acid hydrolysis of biomass}

Xylose is the major carbohydrate in the prehydrolyzate liquor and the largest component of hemicellulose. The highest yield of xylose measured in the prehydolyzate, $83 \%$, was generated after a pretreatment at $1.2 \%$ acid, $140^{\circ} \mathrm{C}$, and 30 min residence time. However, xylose yields at $140{ }^{\circ} \mathrm{C}$ for 30 and $60 \mathrm{~min}$ and $160{ }^{\circ} \mathrm{C}$ for 5 and $15 \mathrm{~min}$ at concentration of $0.9 \%$ acid as well as $140{ }^{\circ} \mathrm{C}$ for $60 \mathrm{~min}$ and $160{ }^{\circ} \mathrm{C}$ for $5 \mathrm{~min}$ at concentration of $1.2 \%$ acid were found to be statistically similar to the highest yield. Figure 1 contains four graphs corresponding to each of the four acid concentration levels. Each graph shows the monomeric xylose measured in the prehydrolyzate for each combination of temperature and residence time. An examination of the graphs shows indications of interaction effects that could explain why several sets of pretreatment combinations generate similarly high xylose yields. Table 2 shows the ANOVA output for several of the major response variables considered in this study, in- cluding xylose. The ANOVA output for xylose confirms the significance of each of the factors as well as each of the interaction terms and shows that temperature and acid concentration offer the greatest influence, about $25 \%$ each, in the variance of the $x y$ lose yield. In general, the importance of temperature, acid concentration, time and interactions between these factors is not too surprising because the relationship has already been investigated using modified Arhenius equations in other studies that have proposed these equations as rate constants in kinetic models to describe the acid hydrolysis of hemicellulose into xylose (Carrasco and Roy, 1992; Baugh and McCarty, 1988).

Figure 1 also highlights the loss of xylose under certain pretreatment conditions. This loss can most likely be attributed to the degradation of xylose into furfural as a result of harsh pretreatment conditions. The major degradation products will be addressed later in more detail. The loss of xylose is first evident at $0.3 \%$ acid and $180{ }^{\circ} \mathrm{C}$ after $15 \mathrm{~min}$. At $0.6 \%$ acid and 160 ${ }^{\circ} \mathrm{C}$ after $30 \mathrm{~min}$ there is a slow decrease in xylose levels as well as a much more rapid decrease at $180^{\circ} \mathrm{C}$ after $5 \mathrm{~min}$. At both $0.9 \%$ and $1.2 \%$ acid the rapid degradation of xylose is clear at both $160{ }^{\circ} \mathrm{C}$ and $180{ }^{\circ} \mathrm{C}$ after $5 \mathrm{~min}$.

The prehydrolyzate can also contain glucose. Table 3 shows the measured glucose monomers liberated from the CBG during the pretreatment averaged across the residence times for each acid concentration and temperature combination. The time variable is omitted because it does not influence glucose yield as strongly as the other factors (ANOVA results not shown), but the standard deviation is included so that the general effect of time on glucose yield in the prehydrolyzate can still be inferred. A clear trend is visible, showing that the increase of temperature or acid concentration results in the increase of glucose in the prehydrolyzate. This follows the logic that as the pretreatment conditions become harsher, the hemicellulose is hydrolyzed faster and more completely, exposing the cellulose to acid hydrolysis as well. Similar trends are reported in a study on the dilute acid pretreatment of corn stover by Lloyd and Wyman (2005). 
Table 2. ANOVA responses for xylose, furfural, and hydroxymethylfurfural (HMF) in the prehydrolyzate, glucose in the hydrolyzate, and total reducing sugars (sum of glucose and xylose) during the pretreatment and enzymatic hydrolysis of coastal Bermuda grass.

\begin{tabular}{|c|c|c|c|c|c|c|c|c|c|c|c|}
\hline \multirow[b]{2}{*}{ Source } & \multirow[b]{2}{*}{ DF } & \multicolumn{5}{|c|}{ Type III sum of squares } & \multicolumn{5}{|l|}{$P$-Value } \\
\hline & & $\begin{array}{r}\text { Xylose in } \\
\text { prehydro- } \\
\text { lysate }\end{array}$ & $\begin{array}{r}\text { Furfural in } \\
\text { prehydro- } \\
\text { lysate }\end{array}$ & $\begin{array}{r}\text { HMF in } \\
\text { prehydro- } \\
\text { lysate }\end{array}$ & $\begin{array}{r}\text { Glucose in } \\
\text { hydro- } \\
\text { lysate }\end{array}$ & $\begin{array}{r}\text { Total } \\
\text { reducing } \\
\text { sugars }\end{array}$ & Xylose & Furfural & HMF & Glucose & $\begin{array}{r}\text { Total } \\
\text { reducing } \\
\text { sugars }\end{array}$ \\
\hline $\mathrm{T}^{*}$ & 3 & 76499.71 & 27467.55 & 1026.81 & 184369.60 & 448978.77 & $<.0001$ & $<.0001$ & $<.0001$ & $<.0001$ & $<.0001$ \\
\hline$C^{* *}$ & 3 & 72045.48 & 2779.12 & 151.33 & 52055.52 & 277733.29 & $<.0001$ & $<.0001$ & $<.0001$ & $<.0001$ & $<.0001$ \\
\hline $\mathrm{T} \times \mathrm{C}$ & 9 & 792.68 & 1579.07 & 178.09 & 14867.76 & 21775.18 & $<.0001$ & $<.0001$ & $<.0001$ & $<.0001$ & $<.0001$ \\
\hline Time & 3 & 55443.03 & 4388.32 & 93.62 & 41856.66 & 172873.57 & $<.0001$ & $<.0001$ & $<.0001$ & $<.0001$ & $<.0001$ \\
\hline $\mathrm{T} \times \mathrm{C} \times$ time & 27 & 36623.21 & 1110.38 & 61.57 & 10667.38 & 83095.35 & $<.0001$ & $<.0001$ & 0.0288 & $<.0001$ & $<.0001$ \\
\hline Error & 64 & 1104.53 & 238.82 & 81.29 & 2075.85 & 21183.18 & & & & & \\
\hline Total & 127 & 296737.85 & 40591.96 & 1718.89 & 330646.35 & 1213135.26 & & & & & \\
\hline
\end{tabular}

${ }^{*} \mathrm{~T}=$ temperature in pretreatment. ${ }^{* *} \mathrm{C}=$ sulfuric acid concentration in pretreatment.

Table 3. Glucose in the prehydrolyzate after the dilute sulfuric acid pretreatment of coastal Bermuda grass.

\begin{tabular}{crr}
\hline $\begin{array}{l}\text { Sulfuric acid } \\
\text { concentration } \\
\%(\mathrm{w} / \mathrm{w})\end{array}$ & Temperature $\left({ }^{\circ} \mathrm{C}\right)$ & $\begin{array}{r}\text { Average glucose } \\
\text { in pre-hydrolyzate } \\
\mathrm{mg} / \mathrm{g} \text { raw biomass }\end{array}$ \\
\hline 0.3 & 120 & $5.93 \pm 0.25$ \\
0.3 & 140 & $6.47 \pm 0.74$ \\
0.3 & 160 & $9.09 \pm 2.72$ \\
0.3 & 180 & $13.30 \pm 4.10$ \\
0.6 & 120 & $6.44 \pm 0.90$ \\
0.6 & 140 & $10.71 \pm 3.79$ \\
0.6 & 160 & $21.67 \pm 6.48$ \\
0.6 & 180 & $24.05 \pm 10.91$ \\
0.9 & 120 & $8.08 \pm 2.14$ \\
0.9 & 140 & $20.22 \pm 9.13$ \\
0.9 & 160 & $32.15 \pm 5.16$ \\
0.9 & 180 & $34.18 \pm 3.14$ \\
1.2 & 120 & $10.55 \pm 4.90$ \\
1.2 & 140 & $28.30 \pm 6.48$ \\
1.2 & 160 & $37.29 \pm 2.17$ \\
1.2 & 180 & $43.43 \pm 15.93$ \\
\hline
\end{tabular}

\subsubsection{Degradation of carbohydrates}

Under harsh conditions, carbohydrates are degraded into furfural and HMF which in turn are degraded into levulinic acid and formic acid, respectively. In this study, even the harshest conditions in the factorial did not generate levulinic acid and formic acid levels in the prehydrolyzate close to reported inhibitory levels (>200 mM) while furfural and HMF were measured well beyond reported inhibitory levels $(>1.0 \mathrm{~g} / \mathrm{L})(\mathrm{Na}-$ varro, 1994; Delgenes et al., 1996; Taherzadeh et al., 1997; Palmqvist and Hahn-Hagerdah, 2000; Almeida et al., 2009). For this reason, Figure 2 shows only the furfural and HMF levels. There is one graph for each acid concentration and one bar for each combination of time and temperature. For ease of comparison, the individual amounts of furfural and HMF have been summed as a single bar in each graph of Figure 2 where $10 \mathrm{mg}$ of furfural or HMF each corresponds to $1 \mathrm{~g} / \mathrm{L}$ of that compound for the $10 \%$ solid loading used in this study. As inferred previously, the degradation product generation inversely reflects the xylose losses seen in Figure 1 which also helps explain why much more furfural than HMF is generated. The general trend seen in each of the graphs is supported by the ANOVA output for furfural and HMF in Table 2, which shows that temperature is the dominating significant effect for both response variables.

All of the factors and the interaction terms are significant for furfural and most are significant for HMF except for the in- teraction between concentration and time and the three-way interaction term.

\subsection{Enzymatic hydrolysis}

After the enzymatic hydrolysis, the hydrolyzate was analyzed for glucose and xylose monomers. Figures 3 shows the levels of monomeric glucose measured in the hydrolyzate for each combination of the factors, temperature, acid concentration, and time. The highest yield of glucose measured in the hydolyzate was $95 \%$ of the theoretical maximum and was generated after a pretreatment with $0.6 \%$ sulfuric acid at $160{ }^{\circ} \mathrm{C}$ for $30 \mathrm{~min}$. Examining both Figure 3 and the output of a statistical multiple comparison of the entire data set (not shown), there are 18 other pretreatment condition sets that produce glucose yields that are similar to the $95 \%$ yield. As with the xylose generation in the prehydrolyzate, there are interaction effects contributing to the multiple pretreatment combinations with similar results, however, this is only part of the explanation. The number of pretreatment combinations that give high glucose yields is also increased by the fact that hemicellulose removal during the pretreatment in the form of either xylose or furfural generation can lead to high glucose yield in the hydrolyzate after the enzymatic hydrolysis. This can be observed upon a review of Figures 1 and 2 in comparison with Figure 3, and this makes sense because the success of the acid pretreatment is based around the concept of hemicellulose removal in order to maximize glucose yield after enzymatic hydrolysis. Since furfural levels are substantially influenced by temperature and xylose levels are influenced by temperature and acid concentration, it would be expected that glucose in the hydrolyzate would be influenced most substantially by temperature followed by acid concentration. The ANOVA output in Table 2 supports this claim. All of the factors and interaction terms significantly contribute to the glucose yield in the hydrolyzate, however, the temperature and concentration terms provide the most influence over the variance making up 55\% and $15 \%$, respectively. Figure 2 shows a loss in glucose yield under a few acid concentrations and residence times, but only for $180^{\circ} \mathrm{C}$. The fact that this apparent degradation happens under harsher conditions than xylose degradation and only at the highest temperature used in this study is reasonable because glucose is a more stable carbohydrate than xylose (Baugh and McCarty, 1988).

Table 4 shows the xylose found in the hydrolyzate. Like the glucose levels in Table 3, the xylose levels in Table 4 have been averaged across the residence times for each acid concentration and temperature combination. The standard deviation is 


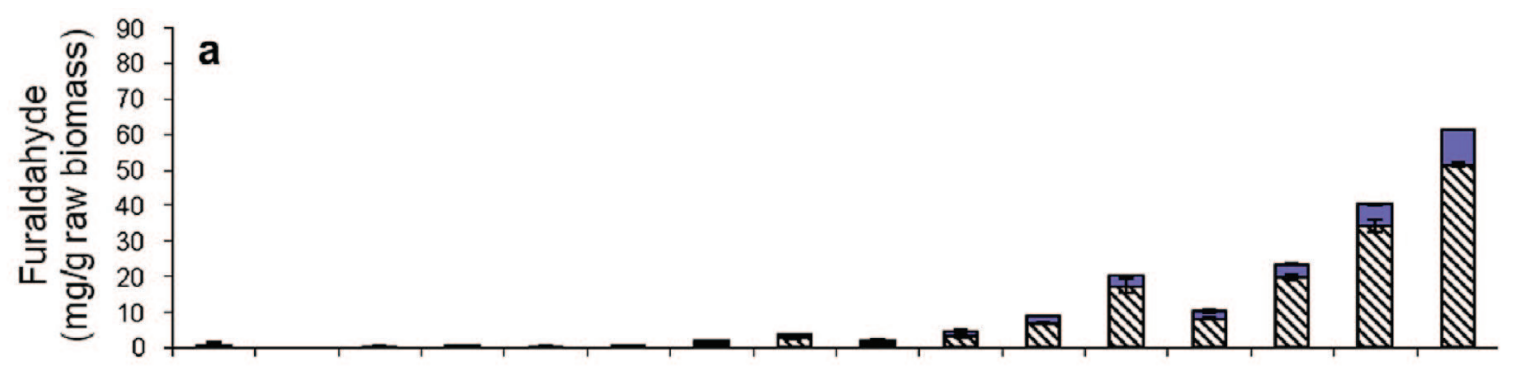

$120^{\circ} \mathrm{C} 120^{\circ} \mathrm{C} 120^{\circ} \mathrm{C} 120^{\circ} \mathrm{C} 140^{\circ} \mathrm{C} 140^{\circ} \mathrm{C} 140^{\circ} \mathrm{C} 140^{\circ} \mathrm{C} 160^{\circ} \mathrm{C} 160^{\circ} \mathrm{C} 160^{\circ} \mathrm{C} 160^{\circ} \mathrm{C} 180^{\circ} \mathrm{C} 180^{\circ} \mathrm{C} 180^{\circ} \mathrm{C} 180^{\circ} \mathrm{C}$

$5 \mathrm{~min} 15 \mathrm{~min} 30 \mathrm{~min} 60 \mathrm{~min} 5 \mathrm{~min} 15 \mathrm{~min} 30 \mathrm{~min} 60 \mathrm{~min} 5 \mathrm{~min} 15 \mathrm{~min} 30 \mathrm{~min} 60 \mathrm{~min} 5 \mathrm{~min} 15 \mathrm{~min} 30 \mathrm{~min} 60 \mathrm{~min}$

Sample

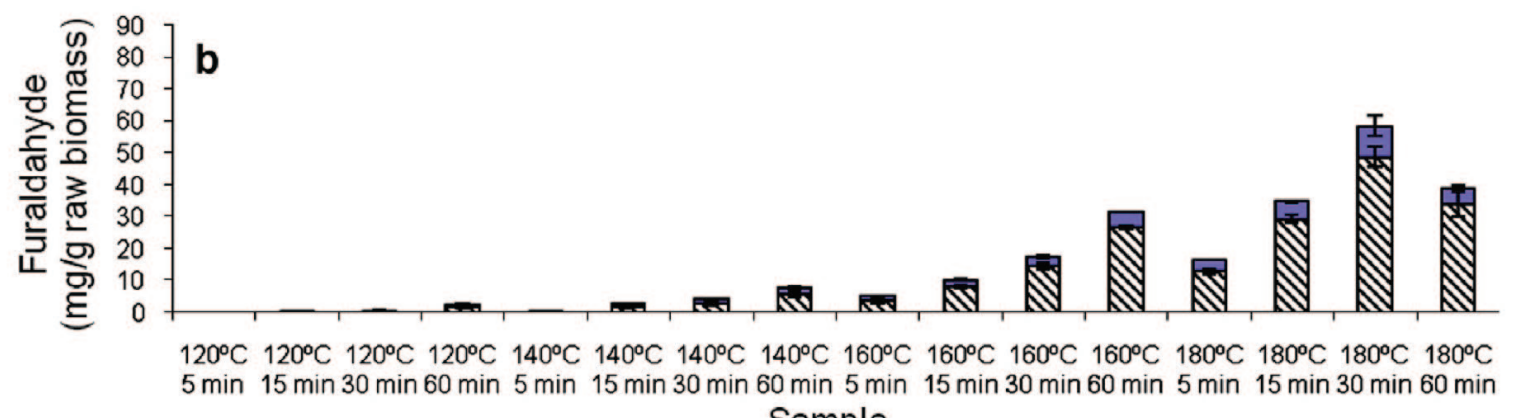

Sample
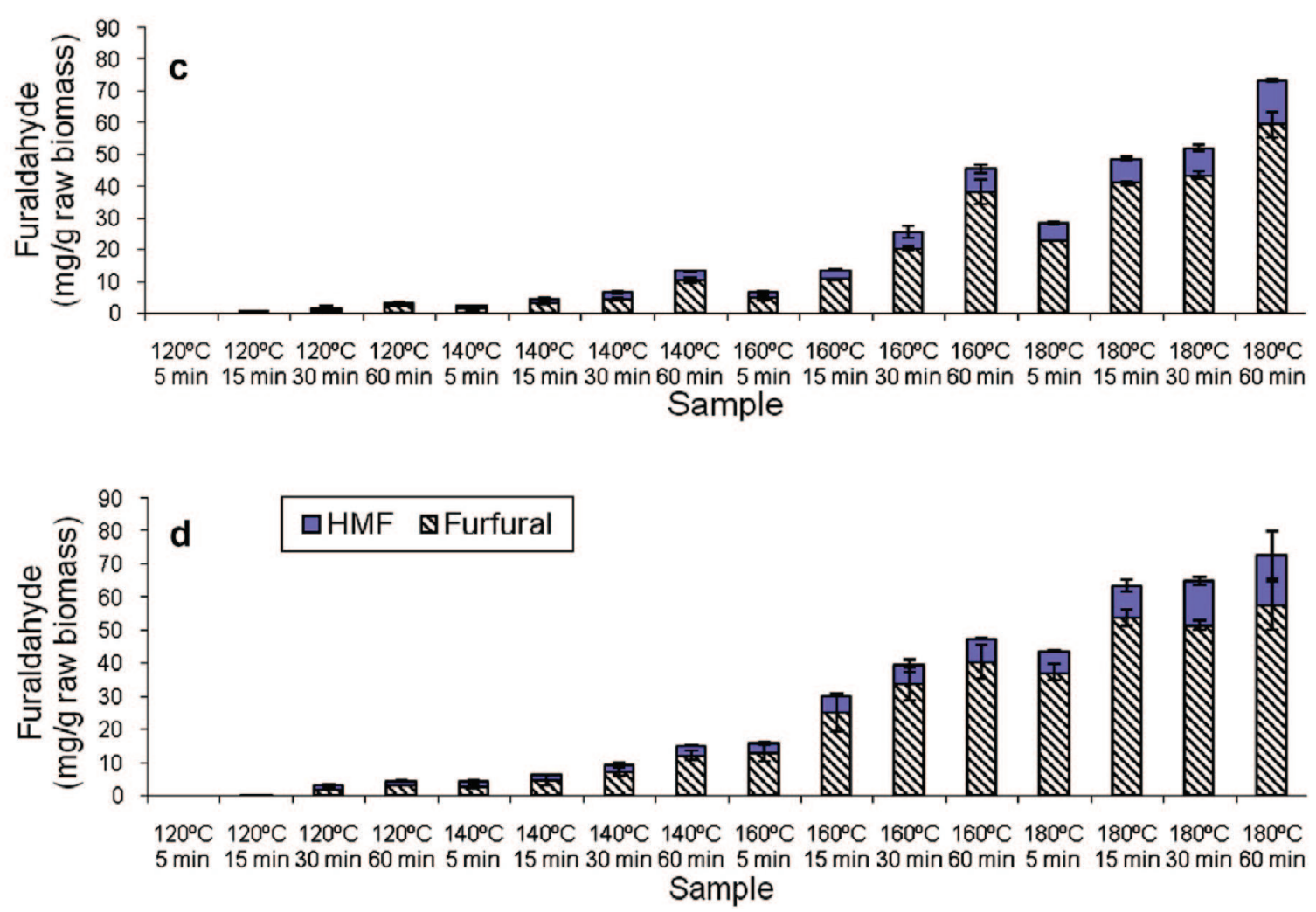

Figure 2. Combined furfural and hydroxymethylfurfural measured in the prehydrolyzate after pretreatment as a function of time and temperature for (a) $0.3 \%$, (b) $0.6 \%$, (c) $0.9 \%$, and (d) $1.2 \%$ sulfuric acid concentration (w/w).

included so that the general effect of time on xylose levels in the hydrolyzate can still be inferred. A clear trend is visible, showing that the increase of temperature or acid concentration results in the decrease of xylose in the hydrolyzate. Only $0.3 \%$ acid at $120{ }^{\circ} \mathrm{C}$ does not appear to follow this trend and this is most likely explained by a weak acid hydrolysis during the pretreatment that did not adequately disrupt the bio- mass. Generally, incomplete acid hydrolysis is what leaves hemicellulose in the solids. Under harsher pretreatments more hemicellulose is removed leaving less in the solids. This correlates to the removal of hemicellulose from the biomass as represented in Figures 1 and 2. Similar trends are reported in a study on the dilute acid pretreatment of corn stover by Lloyd and Wyman (2005). 

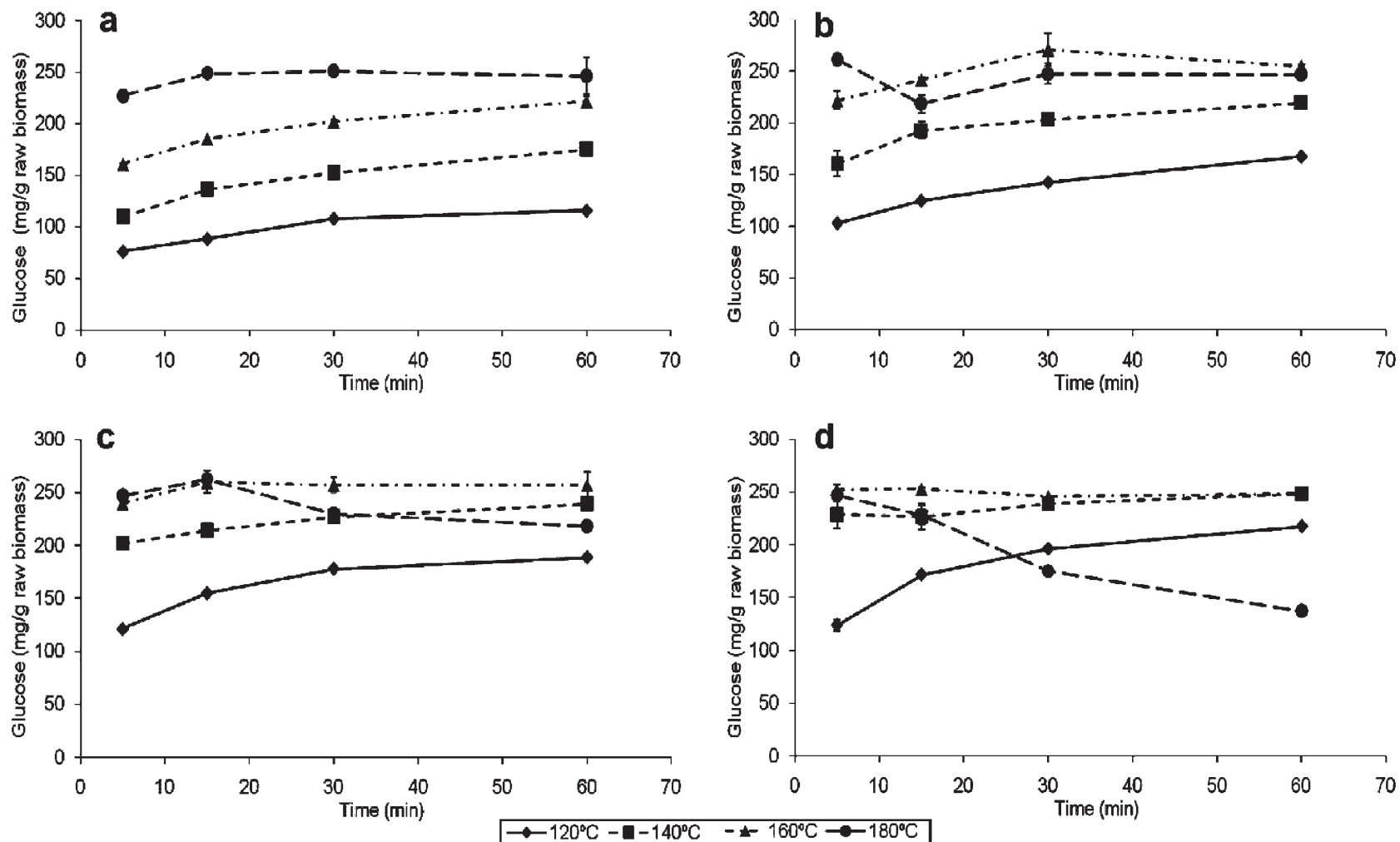

Figure 3. Monomeric glucose measured in the hydrolyzate after enzymatic hydrolysis as a function of time and temperature for (a) $0.3 \%$, (b) $0.6 \%$, (c) $0.9 \%$, and (d) $1.2 \%$ sulfuric acid concentration $(\mathrm{w} / \mathrm{w})$ applied in the pretreatment.

Table 4. Xylose released in the hydrolyzate after enzymatic hydrolysis of coastal Bermuda grass under different pretreatment conditions.

\begin{tabular}{crr}
\hline $\begin{array}{l}\text { Pretreatment conditions } \\
\text { Sulfuric acid } \\
\text { concentration \% }(\mathrm{w} / \mathrm{w})\end{array}$ & $\begin{array}{r}\text { Temperature } \\
\left({ }^{\circ} \mathrm{C}\right)\end{array}$ & $\begin{array}{r}\text { Average xylose } \\
\text { in hydrolyzate mg/g } \\
\text { raw biomass }\end{array}$ \\
\hline 0.3 & 120 & $18.67 \pm 7.41$ \\
0.3 & 140 & $33.61 \pm 8.17$ \\
0.3 & 160 & $28.57 \pm 8.07$ \\
0.3 & 180 & $14.45 \pm 5.99$ \\
0.6 & 120 & $31.14 \pm 7.19$ \\
0.6 & 140 & $27.25 \pm 5.85$ \\
0.6 & 160 & $17.76 \pm 4.54$ \\
0.6 & 180 & $9.14 \pm 3.66$ \\
0.9 & 120 & $30.79 \pm 5.32$ \\
0.9 & 140 & $18.77 \pm 4.87$ \\
0.9 & 160 & $10.50 \pm 4.15$ \\
0.9 & 180 & $3.22 \pm 1.64$ \\
1.2 & 120 & $29.11 \pm 6.51$ \\
1.2 & 140 & $15.37 \pm 3.68$ \\
1.2 & 160 & $6.36 \pm 2.42$ \\
1.2 & 180 & $0.84 \pm 0.97$ \\
\hline
\end{tabular}

The data in this study follow the trends of the data presented in other similar studies looking at the dilute acid pretreatment of herbaceous biomass or crop residues (Sun and Cheng, 2005; Guo et al., 2008). In general, as pretreatment severity increases, hemicellulose is more completely hydrolyzed from the solid biomass. The more complete hydrolysis of hemicellulose appears to correlate with the higher glucose yields after enzymatic hydrolysis even with higher generation of furfurals. Temperature significantly drives the degradation of xylose into furfural and therefore at higher temperatures there is faster xylose degradation. Additionally, the glucose found in the prehydrolyzate increases and the xylose found in the solid biomass decreases as pretreatment severity increases.

\subsection{Total sugars}

All of the available sugars from the biomass must be considered for fermentation into ethanol in order to make cellulosic biomass a feasible choice for ethanol production (Sun and Cheng, 2002). In this study, the total sugars available for fermentation from CBG are the summation of the xylose and glucose monomers found in both the prehydrolyzate and the hydrolyzate. The overall highest yield of total sugars is $97 \%$ of the theoretic maximum, which is obtained with the pretreatment conditions of $0.9 \%$ acid at $160{ }^{\circ} \mathrm{C}$ for $15 \mathrm{~min}$ and $1.2 \%$ acid at $160{ }^{\circ} \mathrm{C}$ for $5 \mathrm{~min}$. Examining all of the pretreatment conditions with total sugar yields of $80 \%$ and greater (20 entries) highlights that while sugar production among these pretreatment conditions remains relatively close, the generation of furfurals varies from $3 \mathrm{mg} / \mathrm{g}$ raw biomass to $37 \mathrm{mg} / \mathrm{g}$ raw biomass (equivalent to furfural concentrations of $0.3-3.7 \mathrm{~g} / \mathrm{L}$, respectively). If the threshold concentration of furfurals where yeast inhibition may begin is assumed to be $1.0 \mathrm{~g} / \mathrm{L}$, based on the other studies cited previously, then this list can be narrowed from 20 entries to 7 . In this shorter list, the pretreatment condition combination of $1.2 \%$ acid at $140{ }^{\circ} \mathrm{C}$ for $30 \mathrm{~min}$ appears to be the best choice based on total sugar yield.

\subsection{Fermentation simulation}

To help verify the best pretreatment parameters, a fermentation simulation step was used to approximate ethanol production relative to changes in ethanol yield by the organism and inhibition caused by furfurals. This step examined the co-fermentation of the sugars from the prehydrolysate and enzymatic hydrolysis streams together.

All ethanol conversion values were taken from the study done by Krishnan et al. (1999) which examined the co-fermentation characteristics of Saccharomyces 1400 (pLNH33) for etha- 

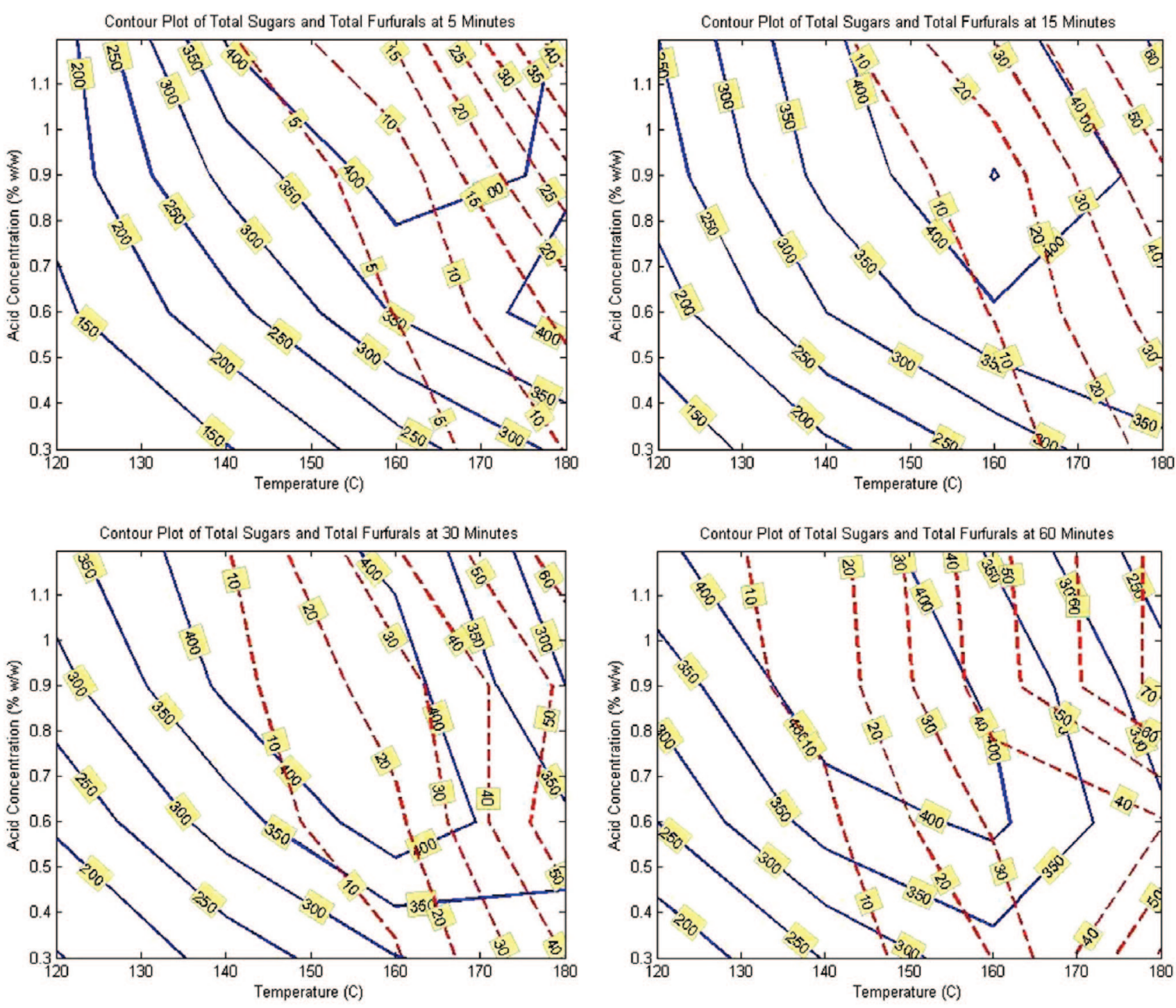

Figure 4. The overlay of contour plots for total sugar yield and total furfural generation as a function of sulfuric acid concentration and temperature at each time level. (Dashed line $=$ furfurals, $\mathrm{mg} / \mathrm{g}$ raw biomass; solid line = total sugars, $\mathrm{mg} / \mathrm{g}$ raw biomass.)

Table 5 The effect of dilute sulfuric acid pretreatment conditions on total sugar production and ethanol yield from coast Bermuda grass.

\begin{tabular}{|c|c|c|c|c|c|c|}
\hline \multicolumn{3}{|c|}{ Pretreatment conditions } & \multirow[b]{2}{*}{$\begin{array}{l}\text { Average furfural, } \\
\mathrm{mg} / \mathrm{g} \text { raw biomass }\end{array}$} & \multirow[b]{2}{*}{$\begin{array}{l}\text { Average HMF, } \\
\text { mg/g raw biomass }\end{array}$} & \multirow[b]{2}{*}{$\begin{array}{r}\text { EtOH } \\
\text { yield }(\%)\end{array}$} & \multirow[b]{2}{*}{$\begin{array}{r}\text { Total sugar } \\
\text { yield (\%) }\end{array}$} \\
\hline $\begin{array}{l}\text { Temperature } \\
\left({ }^{\circ} \mathrm{C}\right)\end{array}$ & $\begin{array}{r}\text { Sulfuric acid } \\
\text { concentration } \%(\mathrm{w} / \mathrm{w})\end{array}$ & $\begin{array}{l}\text { Time } \\
(\mathrm{min})\end{array}$ & & & & \\
\hline 160 & 0.6 & 15 & 8.15 & 2.15 & 74 & 85 \\
\hline 160 & 0.6 & 30 & 14.49 & 2.91 & 52 & 94 \\
\hline 180 & 0.6 & 5 & 12.9 & 3.55 & 57 & 91 \\
\hline 140 & 0.9 & 30 & 4.35 & 1.99 & 79 & 89 \\
\hline 160 & 0.9 & 15 & 10.61 & 2.86 & 76 & 97 \\
\hline 120 & 1.2 & 60 & 3.01 & 1.38 & 75 & 84 \\
\hline 140 & 1.2 & 5 & 2.78 & 1.56 & 77 & 87 \\
\hline 140 & 1.2 & 15 & 4.46 & 1.81 & 76 & 85 \\
\hline 140 & 1.2 & 30 & 6.98 & 2.3 & 83 & 94 \\
\hline 140 & 1.2 & 60 & 12.13 & 2.89 & 69 & 96 \\
\hline 160 & 1.2 & 5 & 12.67 & 3.14 & 65 & 97 \\
\hline
\end{tabular}

nol production from varying mixtures of xylose and glucose in the media. The ethanol conversion of this particular organism was found to vary from 0.40 to $0.48 \mathrm{~g}$ of ethanol per gram of sugar depending on the ratio of xylose to glucose in the media. A greater ratio of xylose to glucose resulted in a lower conversion by the organism. 
A specific relationship between the combined level of furfural and HMF and the rate of ethanol production with Saccharomyces cerevisiae was identified in a study done by Taherzadeh et al. (1997). This study supported the same trend outlined in the other studies mentioned previously by showing the inhibition of the yeast beyond the furfural and HMF concentration of $1 \mathrm{~g} / \mathrm{L}$. An equation for this relationship was approximated from a diagram in the publication using Microsoft Excel to generate a 3rd-order polynomial regression trend line. For the simulation, it was assumed that the recombinant yeast from Krishnan et al. (1999) would be inhibited by the combined furfural and HMF to the same degree as the natural yeast.

Table 5 shows the output of the fermentation simulation with the approximated ethanol yields, exhibiting the expected relationship with combined furfural levels. The combined furfural levels under $10 \mathrm{mg} / \mathrm{g}(1 \mathrm{~g} / \mathrm{L})$ combined with the sugar yields over $90 \%$ give ethanol yields greater than $80 \%$. This confirms that a pretreatment with $1.2 \%$ acid at $140{ }^{\circ} \mathrm{C}$ for $30 \mathrm{~min}$ is an optimal option as well as $0.9 \%$ acid at $160^{\circ} \mathrm{C}$ for $5 \mathrm{~min}$. The simulation also supports the use of $1 \mathrm{~g} / \mathrm{L}$ as the threshold for furfural production when assessing the data for optimal pretreatment conditions.

\subsection{Operating region for optimal pretreatments}

The data presented in this study has identified two optimal pretreatment parameter options. However, if a contour plot for the total sugar data is overlaid on a contour plot of the furfurals data, we can find regions containing pretreatment condition combinations with the potential for high total sugar production and furfural production around $1 \mathrm{~g} / \mathrm{L}$ that are not covered experimentally in this study. Figure 4 shows four contour plots with total sugar yields represented by the solid lines and total furfurals generated represented by the dashed lines. Each plot is at one level of the time factor. Favorable operating regions in between $10 \mathrm{mg}$ furfurals/g raw biomass and $400 \mathrm{mg}$ total sugars/g raw biomass can be found on each plot. These regions do not extend below $0.7 \%$ acid, above $165^{\circ} \mathrm{C}$, or below $125^{\circ} \mathrm{C}$ on any of the plots within the range of the data investigated. The trend of the plots suggests that at higher acid concentrations than examined in this study it may be possible for the favorable region to extend to temperatures lower than 125 ${ }^{\circ} \mathrm{C}$ and at lower residence times than examined in this study, the favorable region might extend to higher temperatures than $165{ }^{\circ} \mathrm{C}$. It would also appear that $0.7 \%$ acid is the minimum concentration to still be able to operate in the favorable region and operating between $0.9 \%$ and $1.2 \%$ acid gives the most options for different temperature and time combinations.

The experimental data suggest both statistically through the significance of interaction effects and visually in contour plots, that there are other non-experimentally found pretreatment combination options that would yield high total sugars. These options could be useful for the future economic analysis of CBG as a feedstock for fuel ethanol production because there may be several different operating points which share similar yields and costs and this could give some flexibility to the design of a process.

\section{Conclusion}

Dilute sulfuric acid pretreatment of coastal Bermuda grass at high temperatures is a technically feasible way to disrupt the biomass for enzymatic hydrolysis and can result in overall yields over $90 \%$ total sugars of the theoretical maximum. In the determination of the optimal pretreatment conditions, i.e. sulfuric acid concentration, temperature, and treatment time, the formation of furfural and HMF (sugar degradation products) during the pretreatment needs to be accounted because of their inhibition to the subsequent fermentation process.

Acknowledgments - The authors would like to thank the North Carolina Biotechnology Center for their funding support and Novozymes North America Inc. (Franklinton, NC, USA) for providing enzymes for this study and their assistance with HPLC analyses. A special thanks to Geoffrey Moxley and Kevin Powell for their assistance in running the HPLC units.

\section{References}

Almeida, J., Bertilsson, M., Gorwa-Grauslund, M., Gorsich, S., Gunnar, L., 2009. Metabolic effects of furaldehydes and impacts on biotechnological processes. Appl. Micribiol. Biotechnol. 82, 625-638.

Baugh, K., McCarty, P., 1988. Thermochemical pretreatment of lignocellulose to enhance methane fermentation: I monosaccharide and furfurals hydrothermal decomposition and product formation rates. Biotechnol. Bioeng. 31, 50-61.

Carrasco, F., Roy, C., 1992. Kinetic study of dilute-acid prehydrolysis of xylan-containing biomass. Wood Sci. Technol. 26, 189-208.

Delgenes, J., Moletta, R., Navarro, J., 1996. Effects of lignocellulose degradation products on ethanol fermentation of glucose and xylose by Saccharomyces cerevisiae, Zymomonas mobilis, Pichia stipitis, and Candida shehatae. Enzyme Microb. Technol. 19, 220-225.

Eggeman, T., Elander, R., 2005. Process and economic analysis of pretreatment technologies. Bioresour. Technol. 96, 2019-2025.

Ghose, T. K., 1987. Measurement of cellulases activities. Int. Union Pure Appl. Chem. 59, 257-268.

Guo, G. L., Chen, W. H., Chen, W. H., Men, L.C., Hwang, W. S., 2008. Characterization of dilute acid pretreatment of silver grass for ethanol production. Bioresour. Technol. 99, 6046-6053.

Han, J., Rowell, J., 1997. Chemical composition of agro-based fibers. In: Rowell, R. M., Young, A. R., Rowell, J. (Eds.), Paper and Composites from Agro-based Resources. CRC Lewis Publishers, New York, pp. 81-134.

Holtzapple, M. T., Ripley, E. P., Nikolaou, M., 1994. Saccharification, fermentation, and protein recovery from low-temperature afex-treated coastal Bermuda grass. Biotechnol. Bioeng. 44 (9), 1122-1131.

Kim, S., Holtzapple, M. T., 1987. Effect of structural features on enzyme digestibility of corn stover. Bioresour. Technol. 97, 583-591.

Krishnan, M.S., Ho, N. W. Y., Tsao, G. T., 1999. Fermentation kinetics of ethanol production from glucose and xylose by recombinant Saccharomyces 1400 (pLNH33). Appl. Biochem. Biotechnol. 77-79, 373-388.

Lloyd, T., Wyman, C., 2005. Combined sugar yields for combined dilute acid pretreatment of corn stover followed by enzymatic hydrolysis of the remaining solids. Bioresour. Technol. 96, 1967-1977.

Moiser, N., Wyman, C., Dale, B., Elander, R., Lee, Y. Y., Holtzapple, M., Ladisch, M., 2005. Features of promising technologies for pretreatment of lignocellulosic biomass. Bioresour. Technol. 96, 673-686.

Navarro, A., 1994. Effects of furfural on ethanol fermentation by Saccharomyces cerevisiae: Mathematical models. Curr. Microbiol. 19, 87-90.

Palmqvist, E., Hahn-Hagerdah, B., 2000. Fermentation of lignocellulosic hydrolyzates II: Inhibitors and mechanisms of inhibition. Bioresour. Technol. 74, 25-33. 
Pearl, I. A., 1967. The Chemistry of Lignin. Marcel Dekker Inc., New York.

Saha, B.C., Iten, L. B., Cotta, M. A., Wu, Y. V., 2005. Dilute acid pretreatment, enzymatic saccharification and fermentation of wheat straw to ethanol. Process Biochem. 40 (12), 3693-3700.

Saha, B.C., Biswas, A., Cotta, M.A., 2008. Microwave pretreatment, enzymatic saccharification and fermentation of wheat straw to ethanol. J. Biobased Mater. Bioenergy 2 (3), 210-217.

Silverstein, R. A., 2004. A comparison of chemical pretreatment methods for converting cotton stalks to ethanol. MS thesis. Raleigh, NC: North Carolina State University, Department of Biological and Agricultural Engineering.

Sluiter, A., 2005. Determination of total solids in biomass. NREL Biomass Analysis Technology Team Laboratory Analytical Procedure \#001. NREL, Golden, CO; online at http://www. nrel.gov/biomass/analytical procedures.html\#lap-001

Sluiter, A., 2005. Determination of ash in biomass. NREL Biomass Analysis Technology Team Laboratory Analytical Procedure \#005. NREL, Golden, CO; online at http://www.nrel.gov/ biomass/analytical procedures.html\#lap-005

Sluiter, A., 2006a. Determination of structural carbohydrates and lignin in biomass. NREL Biomass Analysis Technology Team Laboratory Analytical Procedure \#002. NREL, Golden, CO; online at http://www.nrel.gov/biomass/analytical_procedures.html\#lap-002
Sluiter, A., 2006b. Determination of sugars, byproducts, and degradation products in liquid fraction process samples. NREL Biomass Analysis Technology Team Laboratory Analytical Procedure \#013. NREL, Golden, CO; online at http://www. nrel.gov/biomass/analytical_procedures.html\#lap-013

Solomon, B., Barnes, J., Halvorsen, K., 2007. Grain and cellulosic ethanol: history, economics, and energy policy. Biomass Bioenergy 31, 416-425.

Sun, Y., Cheng, J., 2002. Hydrolysis of lignocellulosic materials for ethanol production: a review. Bioresour. Technol. 83, 1-11.

Sun, Y., Cheng, J. J., 2005. Dilute acid pretreatment of rye straw and bermudagrass for ethanol production. Bioresour. Technol. 96, 1599-1606.

Taherzadeh, M., Eklund, R., Gustafsson, L., Niklasson, C., Liden, G., 1997. Characterization and fermentation of dilute-acid hydrolyzates from wood. Ind. Eng. Chem. Res. 36, 4659-4665.

Wang, Z., Keshwani, D. R., Redding, A. P., Cheng, J. J., 2010. Sodium hydroxide pretreatment and enzymatic hydrolysis of coastal Bermuda grass. Bioresour. Technol. 101, 3583-3585.

Yang, B., Wyman, C. E., 2004. Effect of xylan and lignin removal by batch and flow through pretreatment on the enzymatic digestibility of corn stover cellulose. Biotechnol. Bioeng. 86 (1), 88-95 